\title{
Wellbeing-for patients and doctors
}

\author{
Fiona Godlee editor in chief
}

The BMJ

How should we better prevent falls among older people? This may not seem the most pressing issue for doctors, but, as reported this week (doi:10.1136/bmj.1880), falls are a leading cause of morbidity and death in people aged over 75 , and the costs to health and social care are growing as the population ages.

A range of preventive interventions have been tested. On the basis of evidence from randomised trials, Alison Pighills and colleagues recommend comprehensively assessing and modifying the home environment. But this works only for patients at high risk of falls and if done by an occupational therapist rather than a non-expert health worker.

Among people who have had a fall (about a third of those aged over 65), the fear of falling may further inhibit healthy ageing. Fear causes people to limit their activities, reducing their fitness and quality of life. Health anxiety can have a similar effect, say Erik Hedman-Lagerlöf and colleagues (doi:10.1136/bmj.1774). Formerly known as somatic symptom disorder, health anxiety is common, debilitating, and hard to manage well. It's tempting to just reassure patients, but these authors say this should be avoided. "Reassurance to patients with health anxiety is like an addictive drug_-it provides immediate relief but wears off quickly, sometimes even by the end of the consultation.” A patient who was an adviser for the article confirmed this, noting that being told that "there is nothing wrong with you" is unhelpful and that persistent reassurance only makes him attend more often. Instead the authors suggest acknowledging patients' concerns, validating their symptoms as real, providing an alternative explanation, and offering cognitive behavioural therapy, which has been found to be effective as a first line treatment.

What of the wellbeing of doctors who carry the psychological burden of caring for patients and relatives? In an essay Caroline Elton calls for a radical rethink (doi:10.1136/bmj.1968). Quoting from Samuel Shem's novel The House of God she asks, "How can we care for patients if nobody cares for us?" She says we should learn from a different caring scenario-mother and child-to understand how the burden of responsibility, the fear of making mistakes, and the lack of support from others leave new mothers (and junior doctors) exhausted and resentful, even to the extent of developing hatred and disgust towards their charges. To ward off such damaging emotions the Mayo Clinic and now Stanford Medicine in the US have appointed chief wellness officers, who are charged with implementing strategies to reduce burnout. The BMJ supports Elton's call for similar appointments to the boards of NHS trusts. 